\title{
Job satisfaction and burnout among Greek P.E. teachers. A comparison of educational sectors, level and gender
}

\author{
Satisfacción laboral y burnout de los profesores de la educación física en Grecia \\ Ilias Kroupis ${ }^{1}$, Thomas Kourtessis ${ }^{1}$, Olga Kouli ${ }^{1}$, George Tzetzis ${ }^{2}$, \\ Vassiliki Derri ${ }^{1}$, George Mavrommatis ${ }^{1}$
}

1 School of Physical Education \& Sport Sciences. Democritus University of Thrace. Grecia.

2 School of Physical Education \& Sport Sciences. Aristotle University of Thessaloniki. Grecia.

CORRESPONDENCIA:

Ilias Kroupis

ikroupis@phyed.duth.gr

\begin{abstract}
The purpose of this study was to examine possible differences and relations in Physical Education (P.E.) teachers' perceived job satisfaction and burnout, in relation to educational sector (private vs public), educational level (primary vs secondary) and gender. Two hundred and eighty two P.E. teachers, aged from 24 to 65 years old $(M=43.6, S D=5.45)$, both from elementary and secondary schools, participated in the study. One hundred of them served in private schools and 182 in public ones. Their working exprerience ranged from one to 37 years $(M=14.5, S D=7.23)$. The Employee Satisfaction Inventory (Koustelios \& Bagiatis, 1997) was employed to assess job satisfaction. For the measurement of burnout, Maslach Burnout Inventory (Maslach \& Jackson, 1986), which has been validated for the Greek population, was used. The results revealed a negative relationship between job satisfaction and burnout. Private sector P.E. teachers seem to experience higher job satisfaction and lower burnout compared to their public sector colleagues. Furthermore, P.E. teachers who serve both in elementary and secondary schools, appear to experience higher job satisfaction. Finally, secondary P.E. teachers seem to experience lower burnout compared to their primary education colleagues. No statistically significant differences were found in relation to gender for both job satisfaction and burnout. Overall, it seems that P.E. teachers who work in private schools and/or in secondary education seem to be more satisfied and less burned-out. Implications of the aforementioned observed relationships are discussed.
\end{abstract}

Key words: Private school, public school, primary education, secondary education.

\section{Resumen}

El objetivo de este estudio fue examinar las posibles diferencias y relaciones en la Educación Física (EF) con respecto a la percibida satisfacción laboral y el burnout de los profesores de la EF en relación con el sector de la educación (privado versus público), nivel educativo (primario versus secundario) y género. 282 profesores de la EF participaron en el estudio,con edades entre 24 y 65 años $(M=43.6, S D=5.45)$, tanto de escuelas primarias que de secundarias, 100 siendo de las escuelas privadas y 182 de las públicas. Su experiencia de trabajo varía de uno a 37 años $(M=14.5, S D=7.23)$. Para la evaluación de la satisfacción laboral se empleó el Inventario de Satisfacción del Empleado (ESI) (Koustelios \& Bagiatis, 1997). Para la medición del burnout, se utilizó el Inventario Maslach Burnout (MBI) (Maslach \& Jackson, 1986), que también ha sido validado para la población griega. Los resultados revelaron una relación negativa entre la satisfacción laboral y el burnout. Los profesores de la EF trabajando en las escuelas privadas parecen experimentar mayor satisfacción en el trabajo y menor burnouten comparación con suis colleges del sector público. Además, los profesores de EF trabajando en el mismo tiempo en las escuelas primarias y secundarias, parecen experimentar mayor satisfacción laboral, mientras que los de la secundaria parecen experimentar menor burnout. No se encontraron diferencias estadísticamente significativas en relación con el género, tanto para la satisfacción como para el burnout. Sobre la base de los resultados anteriormente mencionados, resulta que los profesores de EF que trabajan en escuelas privadas o en la educación secundaria parecen estar más satisfechos y menos "desgastados".

Palabras clave: Escuela privada, escuela pública, educación primaria, educación secundaria. 


\section{Introduction}

Satisfaction at work has been a topic of intense research interest during the last three decades. The belief that the level of satisfaction at work can be related to aspects of work behavior such as turnover rates, absenteeism and intention to quit, along with an increasing concern for the meaning of work, have contributed to the growth of the research literature on job satisfaction (Koustelios \& Tsigilis, 2005). In all definitions job satisfaction is presented as a multidimensional concept (Locke, 1976; Rice, McFarlin, \& Bennett, 1989). Several theories like content theories or need-based theories have been used to describe job satisfaction. Content theories attempt to indicate particular values or needs that must be attained for an individual in order to be satisfied with their job (Locke, 1976). Need-based theories on the other hand focus on the individuals (McClelland, 1961). According to these theories, if a job fulfills several important needs of the individual, then it can be a source of satisfaction. Hence, job satisfaction level, reflects the extent to which one's needs are satisfied in a job. Research (Davis \& Wilson, 2000; Shann, 1998) showed that teachers' job satisfaction within the school environment is of great importance, since it affects their performance, which in turn may affect students' performance as well.

Burnout has been linked to various forms of job withdrawal, such as absenteeism, intention to leave the job and actual turnover. There are reports that educators meet conditions of high-stress levels during their career, something which may influence their physical and mental health (Borg, 1990; Farber, 1991; Gugliemi \& Tatrow, 1998). Teacher's burnout, negatively affects their job performance and hence the reduced teaching quality may also affect student's academic performance (Blandford, 2000; Derri \& Pachta, 2007) and/or the educational system in general (Hughes, 2001). The relationship between job satisfaction and burnout has been of great interest for many researchers. Results have revealed moderate to high negative relationship (Bhana \& Haffejee, 1996; Dolan, 1987; Koeske, Kirk, Koeske,\& Rauktis, 1994). Nevertheless, the nature of this relationship is still a cause for questioning. One possibility could be that burnout causes job dissatisfaction (Burke, 1987; Burke \& Greenglass, 1988; Cunningham, 1983; Wolpin, Burke, \& Greenglass, 1991). The opposite hypothesis is that job dissatisfaction could lead to burnout (Dolan, 1987; Leiter, 1988; Stout \& Williams, 1983). While many researchers attempted to investigate the relationship between job satisfaction and burnout within education, research within the context of physical education is rather limited.
Liu and Ramsey (2008) examined teacher's satisfaction on various aspects of their job, such as work conditions, compensation, gender, or years of teaching. According to the researchers, teachers in the United States were least satisfied with work conditions and compensation. Greek educators from both primary and secondary education were satisfied with the job itself and supervision, while they were dissatisfied with pay and promotional opportunities (Koustelios, 2001; Koustelios \& Kousteliou, 1998). P.E. teachers from secondary education in Greece, appeared to be more satisfied with the job itself, less satisfied with the supervisor and working conditions and dissatisfied with pay and organization as a whole (Koustelios \& Tsigilis, 2005). Relatively similar results were found by Zournatzi, Tsiggilis, Koustelios and Pintzopoulou (2006) for Greek P.E. teachers coming from both primary and secondary schools. More specifically, primary P.E. teachers revealed slightly higher levels of satisfaction for pay and organization as a whole, while secondary PE teachers showed slightly higher levels of satisfaction for the factors of working conditions, work itself and supervisor. As for the level of education and burnout, research evidence is contradictory. In some studies secondary teachers have higher levels in depersonalization and reduced personal accomplishment (hence bigger burnout) (Anderson \& Iwanicki, 1984; Kantas \& Vassilaki, 1997; Kouli et al., 2015; Schwab \& Iwanicki, 1982). In other studies no statistically significant differences were found in the most important dimension of burnout, i.e. emotional exhaustion (Byrne, 1991; van Horn, Schaufeli, Greenglass,\& Burke, 1997). Greek P.E. teachers reported relatively low levels of emotional exhaustion and depersonalization (Koustelios, 2003), in comparison to the levels presented by Maslach and Jackson (1986). Koustelios and Tsigilis (2005) also reported low levels of burnout for Greek secondary P.E. teachers. Greek primary P.E. teachers presented significantly higher levels of emotional exhaustion, higher depersonalization and lesser feelings of personal achievement in relation to their secondary colleagues (Tsigilis, Zournatzi,\& Koustelios, 2011) meaning much higher burnout. These results compared with the results from the Kantas and Vassilaki (1997) research for Greek teachers, showed that primary Greek P.E. teachers had similar levels of burnout, compared to secondary teachers or other subject's educators. In the secondary level however, the P.E. teachers appeared to be less burned out compared to other subject's educators (Tsigilis et al. 2011).

It has been stated that the privatization of education has been a central aspect of neoliberal policies traced in many developed and developing countries 
(Levin, 2001; Papanastasiou \& Zembylas, 2005; Tooley, 2001). Comparisons between private and public school teachers (conducted mainly in the US), have shown that private school teachers seem to be more satisfied with their jobs than their colleagues in public schools (Alt \& Peter, 2002; Perie, Baker, \& Whitener, 1997). Relative studies, measuring job satisfaction between private and public school teachers from other countries are limited. Tsigilis, Zachopoulou and Grammatikopoulos (2006) compared job satisfaction among private and public kindergarten teachers in Greece. According to the results, public kindergarten teachers were more satisfied with pay and supervision compared to their private colleagues. Russell, Altmaier and Van Velzen (1987), report that level of education (primary/secondary) is correlated with burnout. In the research of Tsigilis et al. (2006) no statistical differences were found between private and public kindergarten teachers in emotional exhaustion.

It seems that there are no clear results concerning the role of gender in job satisfaction. Antoniou, Kourtessis, Koustelios and Papaioannou (2007) reported that no differences in job satisfaction were found between male and female P.E. teachers. The same results were mentioned in Liu and Ramsey's (2008) study. In another study though, female teachers were more satisfied than their male colleagues in the working conditions factor (Koustelios, 2001). Russell, Altmaier and Van Velzen (1987), report that factors such as gender and age are correlated with burnout. In most studies men appear to have higher levels of depersonalization in comparison to women (Greenglass \& Burke, 1988; Greenglass, Burke, \& Ondrack, 1990; Schwab \& Iwanicki, 1982). For the other two aspects of burnout, emotional exhaustion and reduced personal accomplishment, findings are contradictory in relation to gender. In other research (Koustelios, 2003), no gender differences were found for Greek P.E. teachers in relation to burnout.

Based on the above, teachers' job satisfaction and burnout seems to affect teaching quality. This seems to be the case for P.E. specialists as well. Therefore, it seems of great importance to investigate whether particular factors could affect job satisfaction and burnout levels. In the present study such factors were school level (primary/secondary), school sector (private/ public) and gender. So, the purpose of this study was to investigate the relationship between job satisfaction and burnout for P.E. teachers and compare it with previous studies, to investigate possible differences in job satisfaction and burnout among P.E. teachers according a) to the school (private/public) they work, b) to the school level (primary/secondary/primary + secondary) they teach and c) to their gender. Based on the literature as discussed above we developed the following hypotheses: Hypothesis one: Job satisfaction dimensions of P.E. teachers will have a negative correlation with their burnout dimensions. Hypothesis two: P.E. teachers who work in private schools will have different job satisfaction and burnout levels than those who work at public schools. Hypothesis three: P.E. teachers who work in primary education will have different job satisfaction and burnout levels than those who work at secondary education. Hypothesis four: men and women P.E. teachers will have different job satisfaction and burnout levels. The findings will help school principals and curriculum designers to make positive decisions towards achieving more satisfied and less burn out in P.E. teachers. More satisfied and less burned out P.E. teachers might enhance teaching quality.

\section{Method}

\section{Participants}

Participants were 282 Greek P.E. teachers from primary and secondary public and private schools; 182 were teaching in public schools and 100 in private schools; 136 (48.2\%) were teaching in primary schools, $116(41.1 \%)$ in secondary schools, 21 (7.4\%) in both primary and secondary, while nine did not clarify the school level. As far as gender is concerned, 137 were male (48.6\%) and 145 female (51.4\%). Their age was 24 to $65(M=43.6$; $S D=5.45)$ while their school teaching experience was one to 37 years $(M=14.5$; $S D=$ 7.23). The sample came from Attiki-Athens, due to the large number of private schools included, in order to obtain a sufficient number of private P.E. teachers.

\section{Measurements}

The Employee Satisfaction Inventory (ESI) (Koustelios \&Bagiatis, 1997) was used to assess P.E. teacher's job satisfaction. ESI consists of 24 items, which measures six aspects of a job: the work itself (four items, e.g., my job is boring), pay (four items, e.g., paid less than I deserve), promotion (three items e.g., my perspective for promotion-development is very limited), supervision (four items, e.g., my supervisor is rude), working conditions (five items, e.g., dangerous for my health) and organization as a whole (four items, e.g., the best school/institution I've ever worked). The internal consistencies (Cronbach's alpha) for each aspect were: for work itself (.77), for pay (.79), for promotion (.62), for supervision (.82), for working conditions (.80) and for 
organization as a whole (.76). Responses were given to a 5-point scale ranging from strongly agree (5) to strongly disagree (1).

The educator's version of the Maslach Burnout Inventory (MBI-ES, Maslach \& Jackson, 1986), which has been modified and validated for the Greek population (Kantas \& Vassilaki, 1997; Kokkinos, 2006), was used to measure job burnout. The inventory consists of twenty two items which measure the three dimensions of burnout: emotional exhaustion (nine items, e.g., at the end of the school day I feel exhausted) which describes feelings of being emotionally overextended and exhausted by work, depersonalization (five items, e.g., I feel disappointed by my job) which describes a cynical attitude and impersonal response between oneself and service recipients, and personal accomplishment (eight items, e.g., I've achieved many worthy things in my job) which describes feelings of efficacy and achievement in one's work with people. The internal consistencies (Cronbach's alpha) for each aspect were: for emotional exhaustion (.81), for depersonalization (.60) and for personal accomplishment (.86). For emotional exhaustion and depersonalization, high mean scores represent higher levels of burnout, whereas for personal accomplishment, low mean scores represent higher levels of burnout. Responses were given to a 7-point Likert scale ranging from never (0) to every day (6).

\section{Design and Procedure}

The design of the study was to administer the ESI and MBI questionnaires to P.E. teachers during P.E. consultants' meetings. In these meetings, P.E. teachers from all over Attiki region were gathered by their consultant's in order to attend extra education or discuss every-day school issues. The questionnaires were handed to P.E. teachers when entering the class and returned by them on their way out. Just before the meeting started, instructions about the questionnaires were given to the participants by the researchers. According to ethical standards, it was made clear to the participants that participation was voluntary and anonymous. It was also made clear that their responses would be held in strict confidence and would be used for academic purposes only. Moreover, the specific questionnaires are widely used in many countries for similar reasons. Some limitations should be taken into consideration: a) results cannot be generalized to other subjects other than physical education; b) because of the nature of the particular P.E. meetings (restricted time, agenda), it would be possible that participants did not give the proper devotion while answering the questionnaires; $c$ ) at the time that this study was held, Greece was going through some rough socioeconomic changes, especially in the public sector, where some serious budget and wage cuts had been administered. This situation might have influenced participants' answers.

\section{Data analysis}

There were three independent variables in the present study: school sector (public/private), school level (primary/secondary/primary+secondary) and gender. Nine factors were used: six from the ESI and three from the MBI questionnaire. Cronbach's alpha was used to assess the internal consistency of subscales. Pearson correlation analysis was used to examine the multivariate relationship between job satisfaction and burnout. MANOVA's and ANOVA's were used to investigate possible differences between the subscales of independent variables. SPSS 18 was used for computing all the above calculations. Significance level was set to .05.

\section{Results}

In Table 1 the Pearson correlation matrix, mean values, Standard Deviation and Cronbach's alpha rates, regarding job satisfaction and burnout of P.E. teachers, are presented. The results confirmed the hypothesis that the two concepts would be correlated, since all the subscales of job satisfaction were negatively correlated with the main aspect of burnout, being emotional exhaustion. That means that when emotional exhaustion for P.E. teachers increases, their perceived job satisfaction decreases (and vice versa).

\section{Differences due to school sector}

In Table 2 the means and the Standard Deviation of the ESI subscales for the school sector (public/private) are presented. The overall analysis was significant $\left(F_{(6,213)}=37.95, p<.001\right)$. The findings confirmed the hypothesis that statistically significant differences for job satisfaction would occur between P.E. teachers in relation to school sector (private/public). In the following analysis of variance (ANOVA's), statistically significant differences were revealed between teachers in private and public schools in all depended variables. P.E. teachers working in private schools had higher scores in all the subscales of the ESI questionnaire concerning job satisfaction. In other words P.E. teachers working in private schools were more satisfied than their public colleagues. 
Table1. Correlation matrix, descriptive statistics and Cronbach's alpha of the ESI and MBI subscales

\begin{tabular}{|c|c|c|c|c|c|c|c|c|c|c|c|}
\hline Subscales & 1 & 2 & 3 & 4 & 5 & 6 & 7 & 8 & $M$ & $S D$ & $\alpha$ \\
\hline 1. working conditions & 1.00 & & & & & & & & 3.86 & .79 & .76 \\
\hline 2. pay & $.50 * *$ & 1.00 & & & & & & & 2.25 & 1.12 & .84 \\
\hline 3. promotion & $.48^{* *}$ & $.54 * *$ & 1.00 & & & & & & 2.46 & .95 & .73 \\
\hline 4. work itself & $.26 * *$ & .12 & $.20 * *$ & 1.00 & & & & & 4.28 & .57 & .70 \\
\hline 5. supervision & $.34 * *$ & $.17 * *$ & $.19 * *$ & $.30 * *$ & 1.00 & & & & 4.06 & .72 & .85 \\
\hline 6. organization as a whole & $.53 * *$ & $.32 * *$ & $.38 * *$ & $.37 * *$ & $.61 * *$ & 1.00 & & & 3.41 & .85 & .76 \\
\hline 7. emotional exhaustion & $-.31 * *$ & $-.28 * *$ & $-.27 * *$ & $-.44 * *$ & $-.31 * *$ & $-.29 * *$ & 1.00 & & 19.82 & 9.94 & .82 \\
\hline 8. personal accomplishment & .041 & -.07 & .013 & $.28 * *$ & .08 & $.14^{*}$ & $-.20 * *$ & 1.00 & 40.91 & 5.9 & .76 \\
\hline 9. depersonalization & -.070 & -.05 & -.034 & $-.40 * *$ & $-.24 * *$ & $-.17 * *$ & $.36 * *$ & $-.40 * *$ & 3.04 & 3.67 & .59 \\
\hline
\end{tabular}

Note: ${ }^{*} p<.01,{ }^{*} p<.05$

Table 2. Means of the ESI subscales for school sector

\begin{tabular}{lccc}
\hline Job satisfaction factors & School & M & SD \\
\hline working conditions & private & $4.41 *$ & .55 \\
& public & $3.49 *$ & .73 \\
pay & private & $3.11^{*}$ & 1.01 \\
& public & $1.75^{*}$ & .86 \\
promotion & private & $3.13^{*}$ & .86 \\
\multirow{2}{*}{ work itself } & public & $2.05^{*}$ & .73 \\
& private & $4.38^{*}$ & .49 \\
supervision & public & $4.19 *$ & .61 \\
& private & $4.19 *$ & .67 \\
Organization as a whole & private & $3.63^{*}$ & .74 \\
& public & $3.21 *$ & .82 \\
\hline
\end{tabular}

Note: ${ }^{*}=$ statistically different, $p<.05$

Table 3. Means of the MBI subscales for school sector

\begin{tabular}{llcc}
\hline Burnout factors & school & M & SD \\
\hline \multirow{2}{*}{ Emotional exhaustion } & private & $17.09 *$ & 9.34 \\
& public & $21.12^{*}$ & 10.24 \\
Personal & private & 40.78 & 5.21 \\
accomplishment & public & 41.40 & 5.93 \\
depersonalization & private & 2.38 & 3.37 \\
& public & 3.02 & 3.62 \\
\hline
\end{tabular}

Note: ${ }^{*}=$ statistically different, $p<.05$

In Table 3 the means of the MBI subscales for the school sector (private/public) are presented. The overall (MANOVA) analysis was significant $\left(F_{(3,194)}=\right.$ $3.443, p<.05)$. The findings confirmed the hypothesis that statistically significant differences for burnout would occur between P.E. teachers in relation to school sector (private/public). In the separate analysis of variance (ANOVA's) that followed, statistically significant differences were only found for emotional exhaustion, the main aspect of burnout. In other words P.E. teachers working in public schools experienced more burnout symptoms than their private colleagues.

\section{Differences due to school level}

In Table 4 the means of the ESI subscales for the school level (primary/secondary/primary+secondary) are presented. The overall (MANOVA) analysis was significant $\left(F_{(12,408)}=1.889, p<.05\right)$. The findings confirmed the hypothesis that statistically significant differences for job satisfaction would occur between P.E. teachers in relation to school level (primary/secondary/primary+secondary). In the separate analysis of variance (ANOVA's) that followed, statistically significant differences were found for working conditions, pay, promotion and supervision. For tracing the statistically significant differences, the multiple comparison $L S D$ test was applied and results revealed statistically significant differences between primary and the other two levels (secondary and primary+secondary). Moreover, P.E. teachers who worked at the same time in both primary and secondary level (primary+secondary), scored higher scores in all subscales. In other words P.E. teachers working in primary schools were the least satisfied than all of their colleagues. Moreover, P.E. teachers working in primary and secondary schools seemed to be more satisfied than P.E. teachers working only in primary or in secondary schools.

In Table 5 the means of the MBI subscales for the school level (primary/secondary/primary+secondary) are presented. The overall (MANOVA) analysis was significant $\left(F_{(6,374)}=3.196, p<.01\right)$. The findings confirmed the hypothesis that statistically significant differences for burnout would occur between P.E. teachers in relation to school level (primary/secondary/primary+secondary). In the separate analysis of variance (ANOVA's) that followed, statistically significant differences were only found for emotional exhaustion, the main aspect of burnout. For tracing the statistically significant differences, the multiple comparison LSD test was applied and results revealed statistically significant differences between primary and secondary levels. In other words P.E. teachers working in primary schools experienced more burnout symptoms than their secondary colleagues. 
Table 4. Means of the ESI subscales for school level

\begin{tabular}{|c|c|c|c|}
\hline Job satisfaction factors & School & $M$ & $S D$ \\
\hline \multirow{3}{*}{ working conditions } & primary & $3.67^{*+}$ & .78 \\
\hline & secondary & $3.98^{*}$ & .80 \\
\hline & primary+secondary & $4.22^{\dagger}$ & .45 \\
\hline \multirow{3}{*}{ pay } & primary & $2.01^{*+}$ & 1.01 \\
\hline & secondary & $2.49^{*}$ & 1.24 \\
\hline & primary+secondary & $2.72^{\dagger}$ & 1.00 \\
\hline \multirow{3}{*}{ promotion } & primary & $2.25^{* \dagger}$ & .80 \\
\hline & secondary & $2.56^{*}$ & 1.04 \\
\hline & primary+secondary & $2.98^{+}$ & .80 \\
\hline \multirow{3}{*}{ work itself } & primary & 4.18 & .63 \\
\hline & secondary & 4.33 & .51 \\
\hline & primary+secondary & 4.39 & .44 \\
\hline \multirow{3}{*}{ supervision } & primary & $3.95^{* \dagger}$ & .70 \\
\hline & secondary & $4.16^{*}$ & .68 \\
\hline & primary+secondary & $4.36^{\dagger}$ & .70 \\
\hline \multirow{3}{*}{ organization as a whole } & primary & 3.24 & .85 \\
\hline & secondary & 3.44 & .84 \\
\hline & primary+secondary & 3.73 & .70 \\
\hline
\end{tabular}

Note: ${ }^{*}{ }^{\dagger}=$ statistically different, $p<.05$

Table 5. Means of the MBI subscales for school level

\begin{tabular}{lllr}
\hline \multicolumn{1}{c}{ Burnout factors } & \multicolumn{1}{c}{ school } & \multicolumn{1}{c}{ M } & \multicolumn{1}{c}{ SD } \\
\hline \multirow{3}{*}{ Emotional exhaustion } & primary & $21.65^{*}$ & 10.16 \\
& secondary & $16.79^{*}$ & 9.05 \\
& primary+secondary & 18.86 & 10.53 \\
& primary & 41.74 & 5.46 \\
\multirow{2}{*}{ Personal accomplishment } & secondary & 40.53 & 6.15 \\
& primary+secondary & 40.57 & 4.72 \\
\multirow{2}{*}{ depersonalization } & primary & 3.14 & 3.72 \\
& secondary & 2.21 & 3.13 \\
& primary+secondary & 3.21 & 4.34 \\
\hline
\end{tabular}

Note: * = statistically different, $p<.01$

\section{Differences due to gender}

No gender differences were found either for job satisfaction $\left(F_{(6,213)}=1.323, p>.05\right)$ or burnout $\left(F_{(3,194)}=\right.$ $1.361, p>.05)$ of P.E. teachers. The findings did not confirm the hypothesis that statistically significant differences for job satisfaction or burnout would occur between P.E. teachers in relation to gender. In other words the gender factor did not affect job satisfaction or burnout levels among P.E. teachers.

\section{Discussion}

The purpose of the study was to investigate the relationship between job satisfaction and burnout and to evaluate differences in job satisfaction and burnout among P.E. teachers, of different school sector (private/public), school level (primary/secondary) and gender. The importance of the study lies in the fact that, if it could be determined how factors like school sector or school level affects P.E. teacher's job satisfaction and burnout levels. That could lead to decisions taken by principals or curriculum designers in order to have more satisfied and less burned out P.E. teachers. It was hypothesized that job satisfaction dimensions of P.E. teachers will have a negative correlation with their burnout dimensions, that P.E. teachers who work in private schools will have different job satisfaction and burnout levels than those who work at public schools, that P.E. teachers who work in primary education will have different job satisfaction and burnout levels than those who work at secondary education and finally, that men and women P.E. teachers will have different job satisfaction and burnout levels.

Regarding the relation of the two concepts, the results confirmed hypothesis one, since all the subscales of job satisfaction were negatively correlated with the main aspect of burnout, which is emotional exhaustion. That means that when P.E. teachers' emotional exhaustion increases, their perceived job satisfaction decreases (and vice versa). These results seem to agree with results from other studies, where job satisfaction and burnout presented medium to high negative correlation (Bhana \& Haffejee, 1996; Dolan, 1987; Koeske et al., 1994). Thus, by decreasing the levels of emotional exhaustion, a more satisfied P.E. teacher would exist. On the other hand, a more satisfied P.E. teacher would experience lower levels of emotional exhaustion.

A core finding of the present study, is that private sector P.E. teachers were more satisfied by their jobs and less burned-out than their public sector colleagues. Hypothesis two was thus confirmed by the findings. The results of the present study about job satisfaction and burnout are in compliance with the results of other relative studies (Alt \& Peter, 2002; Densten, 2001; Maslach, Jackson, \& Leiter, 1996; Rohland, Kruse, \& Rohrer, 2004; Schaufeli \& Enzmann, 1998; Shirom \& Ezrachi, 2003). However, there are studies that supported that private sector educators (kindergarten teachers) were less satisfied by their working hours, salary and supervision than their public sector colleagues (Papanastasiou \& Zembylas, 2005; Tsigilis et al., 2006). In the present study, private sector educators exhibited higher satisfaction in all subscales of ESI questionnaire. Furthermore, regarding burnout, differences were only mentioned for emotional exhaustion, where public sector P.E. teachers presented higher scores than their private sector colleagues. This specific dimension is considered to be the most important one, being the main and more autonomous element of burnout. Physical educator specialist who work in public sector 
schools often stress the lack of proper equipment and facilities as a reason that undermines their effort to enhance their teaching quality. Physical education is a subject that, by its nature, depends on equipment and facilities. Given the fact that private sector provides both aforementioned tools, one can understand the results of the current study. Overall, however, the need of more research is obvious since the results of similar studies are rather contradictory. Differences were found in job satisfaction and burnout levels in relation to educational level. The relative research hypothesis was also confirmed. The differences for job satisfaction were found regarding working conditions, pay, promotion and supervision. Primary education teachers exhibited lower scores than secondary education ones, or those who worked in both primary and secondary schools. One very interesting finding was that P.E. teachers who worked both at primary and secondary education schools achieved the highest job satisfaction scores in all subscales. However, this element should be validated with caution, as the number of the specific sample was very small (16 persons) and all subjects came from the private sector. The results of the current study differ slightly from those of Zournatzi et al. (2006), where primary P.E. teachers scored slightly higher in pay and organization as a whole in comparison to their secondary colleagues. One parameter which could possibly affect primary P.E. teachers' job satisfaction is the weekly overload. Primary education P.E. teachers start working for 24 hours per week and many years later they end up working for 21. On the other hand, secondary education P.E. teachers start working for 21 hours per week and they end up working for 16 . However, this may be only one of the dimensions that remain to be investigated. This contradition in itself provides an area for further research and investigation.

Regarding the relationship between burnout and educational level, differences were found in the subscale of the emotional exhaustion. Primary education P.E. teachers exhibited much higher scores compared to their secondary education colleagues. These results are in agreement with the results of other studies (Kokkinos, 2006; Tatar \& Horenczyk, 2003) and especially for P.E. teachers (Tsigilis et al., 2011). In contrast, these results differ from others' (Byrne, 1991; van Horn, Schaufeli, Greenglass, \& Burke, 1997) where no differences were found between primary and secondary teachers or where secondary teachers had higher rates in depersonalization and personal accomplishment (Kantas \& Vassilaki, 1997; Kouli et al., 2015). Since the educational level seems to affect the burnout levels for the Greek P.E. teachers, policy makers should take into consideration that no two-geared
P.E. teachers should exist and decisions should be made aiming for a more balanced P.E. teachers' population in regard to burnout levels. Further research seems urgent since the aforementioned relationship seems to directly affect the professional exhaustion of Greek P.E. teachers.

In the beginning of the current study it was hypothesized that gender would affect job satisfaction and burnout among participants. This hypothesis was not supported by the results. Gender did not seem to influence job satisfaction. These results are in accordance with other studies' results (Antoniou et al., 2007; Liu \& Ramsey, 2008). In the same manner, gender did not influence burnout either. A similar conclusion was found by Koustelios and Tsigilis' (2005), also referring to P.E. teachers. On the contrary, the results of the present study differ from others which refer to other subject teachers, or school staff. For example statistically significant differences were found in relation to depersonalization (Greenglass et al., 1990; Greenglass \& Burke, 1988; Schwab \& Iwanicki, 1982), where males appeared to have higher scores, or in relation to emotional exhaustion (Antoniou, Polychroni, \& Vlachakis, 2006; Kokkinos, 2006; Lau, Yuen, \& Chan, 2005) where the higher scores were achieved by females. The absence of statistically significant differences for only the P.E. teachers in relation to the gender factor could be justified by the nature of the subject of physical education itself. In other words it could be said that the way the lesson of physical education is structured (in Greece), affects similarly both males and females in relation to burnout.

Finally, as for the mean job satisfaction and burnout subscales scores, it seems that P.E. teachers are more satisfied by work itself and supervision, followed by working conditions and organization as a whole. P.E. teachers are dissatisfied by promotion and even more by pay. As for the mean burnout scores and according to the norms of Maslach and colleagues (1996), P.E. teachers in Greece seem to experience medium levels of emotional exhaustion, and low levels of depersonalization and personal accomplishment. In other words they experience medium to low burnout. However, these findings, should be compared with extreme caution to Maslach's norms, since according to Schaufeli and Dierendock (1995), such comparisons should be made with great reservation. They claim that the differences found in the levels of the burnout subscales could be due to the sociocultural differences existing in such countries. Taken from the study, Greek P.E. teachers should perhaps have more chances for promotion and better earnings. Given the current socioeconomic situation though, the latter seems a utopia. 
As for the former promotion opportunities should be given not only from years of duty, but also from other occasions like personal educational development, success in some kind of international games, innovative teaching methods ect.

Despite the moderate levels of burnout that Greek P.E. teachers experience, findings should be further analyzed. In particular, comparing previous scores in P.E. teachers' emotional exhaustion in Greece (Koustelios, 2003; Koustelios \& Tsigilis, 2005; Tsigilis et al., 2011) with the emotional exhaustion score in the present study, showed that it was significantly higher. Since the emotional exhaustion dimension of burnout is considered to be the main and most autonomous element of burnout (Densten, 2001; Maslach et al., 1996; Rohland et al., 2004; Schaufeli \& Enzmann, 1998; Shirom \& Ezrachi, 2003), it could be assumed that Greek P.E. teachers have a tendency to a gradual experience of burnout levels. Causes for such tendency are not easy to be identified. Perhaps a feeling of a lack of real backup on behalf of the state/supervisor, in relation to the rapid negative socioeconomic changes, may lead to greater burnout.

\section{Conclusions}

The implications for the findings suggest that physical educators and curriculum developers should understand the processes and procedures for developing an environment that limits burnout levels and raises job satisfaction. In doing so, primary P.E. teachers should have the opportunity to work in secondary schools, as well as, the promotion criteria could be expanded and be linked not only to years of teaching, and last but not least, that the working environment in public schools could be more supportive providing better infrastructure, human resources, feedback, training programs and so forth.

The limitations of the present study should be kept in mind when interpreting the results. Firstly, it should be noted that since the sample was consisted of P.E. teachers only, that prohibits generalizing the findings to other teachers. Secondly, it must be taken into consideration the time when this study was held. Greece was going through some rough socioeconomic changes and especially in the public sector where some serious budget and wages cuts had been administered. A third limitation concerns the small number of P.E. teachers who worked both in primary and secondary education. This population seemed to score the highest scores in job satisfaction levels and lowest scores in burnout in relation to their colleagues. Future studies could examine if the simultaneous working participation in both primary and secondary school level enhances job satisfaction levels and mediates burnout. Future studies could also investigate whether differences in burnout levels have occurred during this period in other subject teachers as well.

\section{Practical applications}

One aspect for P.E teachers who work in public schools to be more satisfied and less burned out (in comparison to their private colleagues), could be sport equipment and sport facilities. Since private schools are better equipped in this area, public P.E. teachers should try to work out how to provide their classrooms with the best possible sports equipment. The state should provide such equipment, but given the current socioeconomic situation in Greece, where many schools lack proper sports equipment, P.E. teachers in cooperation with the principal should look for solutions.

In order for primary P.E. teachers to be more satisfied and less burned out (in comparison to their secondary colleagues), principals should take into consideration the opportunity for these P.E. teachers to work in secondary education as well. One option could be working in different educational levels (primary / secondary) every one or two academic years, or working in both primary and secondary educational level throughout the same academic year. 


\section{REFERENCES}

Alt, M. N., Peter, K., \& National Center for Education Statistics. (2002). Private schools: A brief portrait. US Dept. of Education, Office of Educational Research and Improvement: National Center for Education Statistics.

Anderson, M. B. G., \& Iwanicki, E.F. (1984). Teacher motivation and its relationship to burnout. Educational Administration Quarterly, 20(2), 109-132. doi: 10.1177/0013161X84020002007

Antoniou, A. S., Polychroni, F., \& Vlachakis, A. N. (2006). Gender and age differences in occupational stress and professional burnout between primary and high-school teachers in Greece. Journal of Managerial Psychology, 21(7), 682-690. doi: 10.1108/02683940610690213

Antoniou, C., Kourtessis, T., Koustelios, A., \& Papaioannou, A. (2007). comparing physical educators' job satisfaction levels with other subject educators. Sport \& Society, 45, 76-82.

Bhana, A., \& Haffejee, N. (1996). Relation among measures of burnout, job satisfaction, and role dynamics for a sample of South African child-care social workers. Psychological Reports, 79(2), 431-434. doi: 10.2466/pr0.1996.79.2.431

Blandford, S. (2000). Managing professional development in schools. London: Routledge Falmer.

Borg, M. G. (1990). Occupational stress in british educational settings: A review. Educational Psychology, 10(2), 103-126. doi: 10.1080/ 0144341900100201

Burke, R. J. (1987). Burnout in police work: An examination of the cherniss model. Group \& Organization Management, 12(2), 174-188. doi: 10.1177/105960118701200205

Burke, R. J., \& Greenglass, E. R. (1988). Career orientations and psychological burnout in teachers. Psychological Reports, 63(1), 107-116. doi: 10.2466/pr0.1988.63.1.107

Byrne, B. M. (1991). Burnout: Investigating the impact of background variables for elementary, intermediate, secondary, and university educators. Teaching and Teacher Education, 7(2), 197-209. doi:10.1016/0742-051X(91)90027-M

Cunningham, W. G. (1983). Teacher burnout-Solutions for the 1980s: A review of the literature. The Urban Review, 15(1), 37-51. doi: 10.1007/ BF01112341

Davis, J., \& Wilson, S. M. (2000). Principals' efforts to empower teachers: Effects on teacher motivation and job satisfaction and stress. The Clearing House, 73(6), 349-353. doi: 10.1080/00098650009599442

Densten, I. L. (2001). Re-thinking burnout. Journal of Organizational Behavior, 22(8), 833.doi: 847. 10.1002/job.115

Derri, V., \& Pachta, M. (2007). Motor skills and concepts acquisition and retention: A comparison between two styles of teaching. RICYDE. Revista Internacional de Ciencias del Deporte, 3(9), 37-47. ISSN-e 18853137

Dolan, S. N. (1987). The relationship between burnout and job satisfaction in nurses. Journal of Advanced Nursing, 12(1), 3-12. doi: 10.1111/ j.1365-2648.1987.tb01297.x

Farber, B. A. (1991). Crisis in education: Stress and burnout in the american teacher. San Francisco: Jossey-Bass.

Greenglass, E. R., \& Burke, R. J. (1988). Work and family precursors of burnout in teachers: Sex differences. Sex Roles, 18(3), 215-229. doi: 10.1007/BF00287791

Greenglass, E. R., Burke, R. J., \& Ondrack, M. (1990). A gender-role perspective of coping and burnout. Applied Psychology, 39(1), 5-27. doi:10.1111/j.1464-0597.1990.tb01035.x

Guglielmi, R. S., \& Tatrow, K. (1998). Occupational stress, burnout, and health in teachers: A methodological and theoretical analysis. Review of Educational Research, 68(1), 61-99. doi: 10.3102/00346543068001061

Hughes, R. E. (2001). Deciding to leave but staying: Teacher burnout, precursors and turnover. International Journal of Human Resource Management, 12(2), 288-298. doi: 10.1080/713769610

Kantas, A., \& Vassilaki, E. (1997). Burnout in Greek teachers: Main findings and validity of the maslach burnout inventory. Work \& Stress, 11(1), 94-100. doi:10.1080/02678379708256826

Koeske, G. F., Kirk, S. A., Koeske, R. D., \& Rauktis, M. B. (1994). Measuring the monday blues: Validation of a job satisfaction scale for the human services. Social Work Research, 18(1), 27-35. doi: 10.1093/ swr/18.1.27

Kokkinos, C. M. (2006). Factor structure and psychometric properties of the Maslach Burnout Inventoryeducators survey among elementary and secondary school teachers in Cyprus. Stress and Health, 22(1), 2533. doi:10.1002/smi.1079

Kouli, O., Kourtessis, T., Tzetzis, G., Karkaletsi, F., Skordilis, E., \& Bonti, E. (2015). Job satisfaction and burnout of greek secondary special education teachers. Journal of Physical Activity, Nutrition and Rehabilitation. Retrieved from http://www.panr.com.cy/index.php/article/ job-satisfaction-and-burnout-of-greek-secondary-special-educationteachers/ e-ISSN: 2421-7824

Koustelios, A. (2001). Personal characteristics and job satisfaction of greek teachers. International Journal of Educational Management, 15(7), 354-358. doi:10.1108/EUM0000000005931

Koustelios, A. (2003). Burnout among physical education teachers in Greece. International Journal of Physical Education, 40(1), 32-38.

Koustelios, A. D., \& Bagiatis, K. (1997). The employee satisfaction inventory (ESI): Development of a scale to measure satisfaction of Greek employees. Educational and Psychological Measurement, 57(3), 469476. doi: 10.1177/0013164497057003008

Koustelios, A., \& Kousteliou, I. (1998). Relations among measures of job satisfaction, role conflict, and role ambiguity for a sample of Greek teachers. Psychological Reports, 82(1), 131-136. doi: 10.2466/ pr0.1998.82.1.131

Koustelios, A., \& Tsigilis, N. (2005). The relationship between burnout and job satisfaction among physical education teachers: A multivariate approach. European Physical Education Review, 11(2), 189-203. doi: 10.1177/1356336X05052896

Lau, P., Yuen, M., \& Chan, R. (2005). Do demographic characteristics make a difference to burnout among Hong Kong secondary school teachers? Social Indicators Research, 71, 491-516. doi: 10.1007/14020-3602-7_17

Leiter, M. P. (1988). Burnout as a function of communication patterns: A study of a multidisciplinary mental health team. Group \& Organization Management, 13(1), 111-128. doi: 10.1177/105960118801300112

Levin, H. M. (2001). Privatizing education: Can the marketplace deliver choice, efficiency, equity, and social cohesion? Boulder, CO: Westview Press.

Liu, X. S., \& Ramsey, J. (2008). Teachers' job satisfaction: Analyses of the teacher follow-up survey in the united states for 2000-2001. Teaching and Teacher Education, 24(5), 1173-1184. doi: 10.1016/j. tate.2006.11.010

Locke, E. A. (1976). The nature and causes of job satisfaction. In M.D. Dunnette (Ed.), Handbook of industrial and organizational psychology (pp. 1319-1328). Chicago: Rand Mcnally.

McClelland, D. C. (1961). The achieving society. New York: Van Nostrand.

Maslach, C., \& Jackson, S. E. (1986). Maslach burnout inventory manual(2nd ed.). Palo Alto, CA: Consulting Psychologists Press.

Maslach, C., Jackson, S. E., \& Leiter, M. P. (1996). Maslach burnout inventory manual (3rd ed.). Palo Alto, C.A.: Consulting Psychologists Press.

Nikolaos, A. (2012). An examination of a burnout model in basketball coaches. Journal of Physical Education and Sport, 12(2), 171.

Papanastasiou, E. C., \& Zembylas, M. (2005). Job satisfaction variance among public and private kindergarten school teachers in $\mathrm{Cy}-$ prus. International Journal of Educational Research, 43(3), 147-167. doi:10.1016/j.ijer.2006.06.009

Perie, M., Baker, D., \& Whitener, S. (1997). Job satisfaction among America's teachers: Effects of workplace conditions, background characteristics and teacher compensation US Department. of Education, Office of Educational Research and Improvement, National Center for Education Statistics.

Rice, R. W., McFarlin, D. B., \& Bennett, D. E. (1989). Standards of comparison and job satisfaction. Journal of Applied Psychology, 74(4), 591. doi:10.1037/0021-9010.74.4.591

Rohland, B. M., Kruse, G. R., \& Rohrer, J. E. (2004). Validation of a singleitem measure of burnout against the Maslach burnout inventory among physicians. Stress and Health, 20(2), 75-79. doi:10.1002/smi.1002

Russell, D. W., Altmaier, E., \& Van Velzen, D. (1987). Job-related stress, social support, and burnout among classroom teachers. Journal of Applied Psychology, 72(2), 269-274. doi:10.1037/0021-9010.72.2.269

Schaufeli, W., \& van Dierendonck, D. (1995). A cautionary note about the cross-national and clinical validity of the cut-off points for the Maslach Burnout Inventory. Psychological Report, 76, 1083-1090.doi: 10.2466/pr0.1995.76.3c.1083

Schaufeli, W., \& Enzmann, D. (1998). The burnout companion to study and practice: A critical analysis. Philadelphia: Taylor \& Francis. 
Schwab, R. L., \& Iwanicki, E. F. (1982). Who are our burned out teachers? Educational Research Quarterly, 7, 5-16.

Shann, M. H. (1998). Professional commitment and satisfaction among teachers in urban middle schools. The Journal of Educational Research, 92(2), 67-73. doi: 10.1080/00220679809597578

Shirom, A., \& Ezrachi, Y. (2003). On the discriminant validity of burnout, depression and anxiety: A re-examination of the burnout measure. Anxiety, Stress \& Coping, 16(1), 83-97. doi: 10.1080/ 1061580021000057059

Stout, J. K., \& Williams, J. M. (1983). Comparison of two measures of burnout. Psychological Reports, 53(1), 283-289. doi: 10.2466/pr0. 1983.53.1.283

Tatar, M., \& Horenczyk, G. (2003). Diversity-related burnout among teachers. Teaching and Teacher Education, 19(4), 397-408. doi: 10.1016/ S0742-051X(03)00024-6

Tooley, J. (2001). The global education industry: Lessons from private education in developing countries. London: Inst of Economic Affairs.
Tsigilis, N., Zachopoulou, E., \& Grammatikopoulos, V. (2006). Job satisfaction and burnout among Greek early educators: A comparison between public and private sector employees. Educational Research and Review, 1(8), 256-261.

Tsigilis, N., Zournatzi, E., \& Koustelios, A. (2011). Burnout among physical education teachers in primary and secondary schools. International Journal of Humanities and Social Science, 7(1), 53-58.

van Horn, J. E., Schaufeli, W. B., Greenglass, E. R., \& Burke, R.J. (1997). A Canadian-Dutch comparison of teacher's burnout. Psychological Reports, 81(2), 371-382. doi: 10.2466/pr0.1997.81.2.371

Wolpin, J., Burke, R. J., \& Greenglass, E. R. (1991). Is job satisfaction an antecedent or a consequence of psychological burnout? Human Relations, 44(2), 193-209. doi: 10.1177/001872679104400205

Zournatzi, E., Tsigilis, N., Koustelios, A., \& Pintzopoulou, E. (2006). Job satisfaction in primary and secondary Physical Education teachers. Sport \& Recreation Management, 3(2), 18-28 